\title{
Organization Of Swimming Lessons In Preschool Institutions
}

\begin{abstract}
Abdullayev Farhod Turdaliyevich, Associate Professor At"Methods Of Organizing Sports Classes"

Center For Scientific And Methodological Support, Retraining And Advanced Training Of Specialists In Physical Culture And Spot Under The Ministry Of Physical Culture And Sports Of The Republic Of Uzbekistan
\end{abstract}

\author{
Abdullayeva Barno Pulatovna, \\ Teacher of Chirchik State Pedagogical Institute in Tashkent \\ region, Uzbekistan
}

\author{
G open access \\ The American Journal of \\ Social Science And \\ Education Innovations \\ JULY 2020 \\ Page No.: 322-330 \\ Volume-II Issue-VII \\ PUBLISHED: 30 JULY 2020 \\ www.usajournalshub.com/inde \\ x.php/tajssei \\ Copyright: Original content \\ from this work may be used \\ under the terms of the \\ Creative Commons Attribution \\ 4.0 licence.
}

\section{Abstract}

The article discusses several significant functions and features of swimming lessons which should be taken into account while organizing swimming lessons specialized for preschool children. Moreover, all necessary rules and principles regarding ensuring the safety of children and hygienic requirements, supply of suitable equipment are presented giving certain examples.

Keywords: Swimming, swimming pool, swimming movement, motion error, exercise, health, safety measures, hygienic requirements, instructors, physical fitness, swimming curricula, formation of swimming skills, equipment, non-standard equipment.

\section{Introduction}

\section{Functions and peculiarities of swimming as a means of physical education}

Swimming is one of the most important parts of raising a child and is a unique type of physical activity. The specific effect of swimming on the child's body is associated with active movements in the aquatic environment. The swimming pool, water games, swimming are convenient for the full physical development of the child.

Preschool physical education instructors and staff are given the most important tasks to save the lives and health of children, improve the physiological functions of the child's body and increase its protective properties. In this regard, a great place in the system of general physical education in kindergarten is given to swimming. Swimming is a very good tool for developing and improving the physical characteristics of a preschool child and has a serious impact on his health. From an early age, one of the most powerful forms of 
exposure to this developing organism is water, air, sun, and physical activity of the child. Swimming:

- calms the body, improves thermoregulatory mechanism, improves the immune system, improves adaptation to various environmental conditions;

- develops self-care skills;

- improves blood circulation and respiratory system, improves heart function, improves chest mobility, respiratory rhythm, increases the vital capacity of the lungs;

- strengthens the musculoskeletal system, properly forms the spine, improves physical condition, prevents the development of flat feet;

- increases work capacity and muscle strength;

The main purpose of swimming lessons for preschool children is to ensure their health, development and comprehensive physical fitness. At the same time, swimming lessons at an early age are also of great importance for the wide involvement of children in rowing, water sports and other popular sports. It is as necessary as skills like running, jumping, cycling and so on. Many well-known swimmers learned to swim at the age of 4-5, and by the age of 6-8 they were already practicing regularly. Therefore, it is very important to determine the ability of children in swimming as early as possible, to form a sharp struggle in this area and the desire to win.

Swimming ability:

- takes care of your health:

Personal hygiene skills:

- Ability to control your body in an unusual environment Health effects of swimming.

Swimming helps to improve the functional capabilities of the nervous system, its autonomous functions, increase the mobility of nervous system processes. This is especially helpful for overly excited children. Water temperature and a smooth cyclic movement have a calming effect on the nervous system, soothe the baby and ensure good sleep, develops strength, speed, agility, flexibility, coordination of movements, endurance in harmony; improves mobility.

During bathing and swimming, special conditions are created for the heart and the entire cardiovascular system. Changes in blood composition occur during swimming, simple bathing, or simply staying in the water.

Swimming exercises strengthen the external respiratory apparatus, increase lung capacity and chest volume, as the density of the water makes it difficult to breathe, and the respiratory muscles become stronger and more developed over time.

Swimming trains proper breathing as you learn the techniques of other sports such as exercise. Since breathing is closely related to the rotation of the arm movement, it is not possible to swim with the chest without short breaths and long exhalations. Breathing, diving, swimming under water increases the ability to tolerate hypoxia, lack of oxygen.

Swimming strengthens the child's body, increases its resistance to temperature changes and protects it from colds. Water has mechanical and thermal effects on the skin. Cleanses the skin, improves skin respiration and strengthens the skin itself.

Swimming affects a child's growth and is an indispensable tool for creating a "muscle corset". Due to the symmetrical movements and the horizontal position of the body, the spine develops properly due to the pressure on the body weight, swimming is a perfect 
corrective exercise that eliminates positions such as knee, scoliosis, kyphosis.

Swimming helps reduce excess fat in the body. However, in very thin children, these activities help to increase subcutaneous fat, which in turn improves strength and muscle size, as well as improving stature.

Swimming, water games, and swimming are good for a child's full physical development. In preschool children, muscle function is not so great that they get tired quickly under static load. Children are more specific to dynamics. During swimming, the tension and relaxation of various muscles change, which increases their performance and strength. In water, the static tension of the body is reduced, the load on the spine of strong and elastic children in water is reduced, in which case the child's stature is properly formed and well developed. At the same time, the active movement of the feet when not supported in the water strengthens the child's feet and prevents the development of flat feet. 1 month of swimming is equivalent to 3-4 months of "dry" physical training.

The value of a swimming program

The ability to swim is an important skill for anyone of any age. Once mastered, swimming is a lifelong pursuit.

Because people don't know how to swim, there are a lot of accidents in the water every year. It is mainly observed in preschool children. According to UNESCO, about 120 people die every year out of every million people living on the planet. According to reports, these are children and adolescents who do not swim. Anyone who doesn't know how to swim in the water or even stand on the surface of the water, even a seemingly harmless body of water, and who falls into the water is in danger. A person who is able to swim once in the water will never risk his life. He knows he can swim to shore or any swimming vehicle or stay on the water until help arrives. Accidents in the water also occur as a result of not knowing the basic rules of behavior in the water while swimming.

Water is man's healer and friend, but he is a cunning enemy of those who do not know how to swim and are unable to stay afloat. You don't have to have special skills to swim. People of any age can swim, including preschoolers. However, swimming techniques in sports are more quickly mastered by children of primary and secondary school age.

Swimming is a skill that is necessary for a person in different situations. This means that mass swimming lessons are of great importance for preschool children. If all children are taught from an early age to behave properly in the water - to sit in the water, to swim at least a short distance, the lives of many children will be protected from misfortune. The enormous effects of swimming on children's bodies are universally recognized, so teaching a child to stand on the water means instilling life skills in him.

The educational significance of swimming

Swimming lessons are very educational. Often, exercise in the water requires the display of a number of personal qualities. In overcoming various difficulties in the process of swimming and managing their emotions, it is very important for the child's vital qualities and character qualities (courage, perseverance, diligence, etc.). Swimming lessons are usually held in a team. Often when playing water games, the actions of one practitioner affect the actions of another. There is a type of coordination of their actions, such as team interests and behaviors, subordination to the individual according to the overall action strategy. This is reflected in many water games and entertainment. Being able to behave, obey the will of the team, find the only right solution, and help a friend regardless of 
personal ambitions. These and many other moral qualities are formed during exercise and especially during swimming.

As a professional physical education instructor, water sports coach, the ability to comprehensively evaluate the content of the exercises used and to identify the possibility of using its various aspects for educational purposes is crucial.

\section{The Main Findings And Results}

\section{Ensuring the safety of swimming lessons in preschools.}

Swimming exercises are allowed for children who have passed a medical examination and pose no risk to health. When conducting swimming lessons, it is necessary to follow the rules of conduct, the schedule of lessons, the prescribed lessons and rest regimes. In the cold season, it is preferable to exercise in a swimming pool after walks.

The following risk factors can be encountered during swimming lessons:

- injury and falls on a smooth wet surface

- Injury and drowning when falling into the water with his head due to lack of water;

- swimming immediately after eating or a lot of physical activity; (The time between meals and swimming should be at least 40 minutes.)

- drowning in swimming;

- swimming in water that does not meet sanitary requirements.

Rescue preparations should be made to prevent drowning during swimming lessons, as well as the availability of first aid kits and clothing in case of injury conditions. During the lessons, the children should follow the order of the lessons. Every trainee should know and follow the following rules of behavior in the swimming pool:

- Listen and complete the task carefully;

- Access to water only with the permission of the physical education instructor;

- Go down the stairs, into the water;

- Do not stand still in the water;

- Do not disturb each other, sway;

- Do not push each other;

- Do not shout;

- Not to seek help falsely;

- Do not drown each other;

- Do not run within the swimming pool;

- Ask to leave if necessary;

- Quick exit by order of the physical education instructor.

The trainer-instructor and physical education instructor must know swimming, know the techniques of swimming and thoroughly know the teaching methodology.

The following rules should be followed for successful training:

- Do not force children to dive, dive into the water, do not say things like "you will swallow the water" by threatening.

All explanations of a methodological and organizational nature are made with the children only when they are on land and the whole group is in the water. Brief commands, instructions, assessments are applied, which should be very clear so as not to reduce the intensity and sensitivity of the movements and so that the children do not get cold.

- Particular attention should be paid to the conduct of the first exercises, the correct choice of existing exercises for mastering should be made according to age, because in 
children, the initial training can have a great psychological impact on their success. increases self-confidence and confidence.

Small accomplishments in education should also be noted, and the whole group or individual children should be applauded and supported.

- If new children are unable to complete the task, the teacher should offer maximum endurance, patience, and other feasible tasks, often due to the teacher's reckless actions.

- When explaining a new exercise, the following key elements should be considered: starting position, form and nature of movement, the most difficult parts.

- Explain and demonstrate the exercise, highlighting what needs to be done to do it correctly, without drawing children's attention to mistakes and shortcomings.

- Each workout should start with a series of simple and straightforward exercises that will allow you to be comfortable in the swimming area, learn the temperature of the water, and feel confident in your abilities.

- When learning new exercises, pay special attention to the instructions on how to avoid common mistakes in them.

- Correct mistakes at the same time without too many comments - this will increase your interest and self-confidence.

- You should not learn more than one or two exercises per session.

\section{Hygienic requirements for training}

Sanitary and hygienic rules and requirements - this is a set of basic rules for the organization of the swimming pool. This document contains all the instructions, requirements and standards that must be strictly and completely followed. Let's look at the most important ones.

What should be near the pool?

- 2 bathrooms;

- Spacious room;

- Toilets;

- Nursing and swimming instructor's room;

- Rooms with technical equipment of the swimming pool;

- Water Analysis Laboratory.

General cleaning in the pool is standard once a month. Water quality control is carried out once a day, microclimate parameters - 2 times a year, air condition, noise and light levels - once a year, bacteriological and parasitological analysis of the water surface - once a quarter.

The recommended time for swimming pool is regulated according to the age of the children: the youngest group - 15-20 minutes, the middle group - 20-25 minutes, the senior and preparatory groups - 25-30 minutes.

In winter, training in the swimming pool should be held after the walk, if it is not possible to do so, then at least 50 minutes should pass between swimming and walking.

Preschoolers are taught $7 \times 3 \mathrm{~m}$ for young children in elementary swimming lessons, up to $0.8 \mathrm{~m}$ deep. It is recommended to use a swimming pool with a large pool - $10 \times 6 \mathrm{~m}$, $12.5 \times 6 \mathrm{~m}$, depth 1.2-1.6 $\mathrm{m}$ to organize classes with a group of children of medium and older groups. The most convenient shape of the pool is a rectangle. But others can be used depending on the circumstances. 
The swimming pool should be equipped with comfortable stairs for children to climb into and out of the water. It is best that the stairs are installed vertically and not far from the pool wall; Mandatory conditions are the presence of handles. To ensure the safety of children and prevent injuries, stairs should be covered with rubber or other non-slip material and should have rubber mats or rubber walkways when exiting the pool and shower.

Child safety handrails will be installed around the perimeter of the pool. If the swimming pool for children is artistically decorated, it is better to have on the walls - a mosaic panel or pictures of fairy-tale heroes. The pool should be equipped with at least two dressing rooms, clothes and towels, sofas. The floor of the dressing room is covered with a rubber mat or wooden grille. The swimming pool should have at least 3-4 showers as well as toilets for children to wash before and after exercise.

Indoor swimming pools should be equipped with ventilation, they should maintain adequate light and air temperature, cleanliness and order. The building should be heated and all passages should be heated to prevent children from getting cold during the entry and exit of the swimming pool. When moving from one room to another, all precautions should be taken to avoid sudden changes in temperature.

In practice, the temperature of the swimming pool in preschools where swimming lessons are held, as a rule, depends on the duration of training, the age of the children and their health. In the initial period, the water temperature in the pool can range from $+30^{\circ}$ to + $32^{\circ} \mathrm{C}$. As the children become accustomed to the water, the temperature gradually drops to the recommended level $\left(+26^{\circ}\right.$ to $+29^{\circ} \mathrm{C}$ ). For healthy and well-groomed children, the pool water temperature can be lowered to $+26^{\circ} \mathrm{C}$ to achieve the greatest effect of hardening. Swimming pool water temperature for older preschoolers is often kept around $+27-28^{\circ} \mathrm{C}$.

\section{Classes and training equipment}

Kindergarten swimming pool should have the necessary equipment for the successful organization of joint play, physical training, successful formation of swimming skills.

It includes:

- air-filled rings of various sizes;

- large foam-plastic and small-sized foam swimming boards;

- horizontal and vertical ring;

- gymnastic sticks;

- special hand-held device (air);

- rubber balls of different sizes and anti-stress;

- Floating and sinking toys.

Equipping all areas of the swimming pool with sports and recreational equipment, including non-standard equipment, will help to create a multi-functional, meaningful, rich, diverse environment during training. Equipment should be durable, safe and lightweight.

An example of non-standard equipment for swimming pools in preschool institutions:

1. Separation paths with bright signs are $12.5 \mathrm{~m} 2-3$ in length from every $1 \mathrm{~m}$

2. $5 \mathrm{~m}$ long rubber walkway $1-2$

3. Carpet path (carpet length $-0.3 \mathrm{~m}$ ) to prevent 5 specially sewn flat feet 1

4. 6 - $8 \mathrm{~m}$ long short lane 5 - 11

5. Foam swimming boards of different sizes 25 
6. Toys and objects of different shapes and sizes 30

7. Sinking toys and objects - in different shapes and sizes 30

8. Toys and equipment that can change their float in different sizes 30

9. Life rescue ring for children from 0.5 to $1.0 \mathrm{~kg} 15$

10. Rubber mat 8

11. Assembly (folds, breathing tube, mask) 25

12. Special hand-held device of various sizes 25

13. Hand shovels of different sizes 25

14. Gymnastic stick 25

15. Foam sticks of different sizes 10

16. Device for connecting tubes (couplings) to foam rods of different sizes 20

17. A device for connecting rods with a sliding plate with a lid 10

18. Additions of different sizes for connecting legs 25

19. Swimming pools 25

20. Stairs to go down to the pool 1

21 . Removable hull on the sides of the pool 2-3

22. Folding handles $1-1.5 \mathrm{~m}$ long on both sides of the pool 12

23. Sliding surface that sinks to the bottom of deep pools 1

24. Plastic sticks $3 \mathrm{~m}$ long 2 - 4

25. Air-filled rings of different sizes 25

26. Rubber balls of different sizes 30

27. Floating ring (horizontal) 10

28. Ring with weight (vertical) 10

29. Foam rectangular plate (connecting plates) with holes for rods 2

30. Separation block (to separate a part of the pool) 1

31. Color floating device (cell) 4

32. Sloping ramp (for watering) 2

33. Swimming goggles 25

34. Rotating, removable rollers to keep children in the water 25

35 . Elements of use for teaching brass and dolphin method 25

36. Belt for swimming exercises 25

37. Referee's whistle 2

38. Stopwatch 2

39. Suspended clock-stopwatch 1

40. Room thermometer 4

41. Thermometer for water 1

The main form of improving a child's health is, of course, exercise and a visit to the swimming pool. Classes to teach children to swim are conducted using health technologies: breathing exercises, elimination of posture defects and prevention of flat feet, exercise.

The use of non-standard tools and equipment in the group allows to attract preschoolers, to expand the material and technical base in kindergarten and in the family, regardless of financial status. Children's interest in various news evokes positive emotions, which improves the child's whole body, mental state.

It is important that such equipment is safe, aesthetically pleasing, age-appropriate for 
children, and functionally attractive.

By engaging in such equipment, children adapt quickly to water, overcoming insecurity and fear without complications. When working with a large group of trainees, nonstandard equipment is used to replicate, reinforce, and improve individual movements, swimming techniques as they master swimming techniques.

A skilled physical education instructor can transform the training into a variety of games, conduct water aerobics, and conduct recreation and entertainment in a variety of ways. Experts suggest that physical education instructors create and use non-standard, useful, and engaging equipment from engaging devices that allow the institution to conduct interesting and useful lessons for students.

The duration of educational activities varies in different age groups. It is determined by age, period of upbringing. At the beginning of the lessons, the training times will be shorter, and then as the children adapt to the water, their duration will gradually increase. The length of time spent in the water also varies in each age group and depends not only on the above reasons, but also on how the joint work of the staff of the preschool is organized.

Swimming lessons are conducted by a physical education instructor with special knowledge. The staff of the institution plays an important role in the preparation and conduct of swimming lessons. The team works closely with the physical education instructor and medical staff. They work in their groups: they follow a training schedule and prepare small groups for them, introduce rules of behavior in the pool, directly during training, undress quickly and learn to dress. Together with the nurse, she determines which of the children needs a patient regimen or exemption from classes, and maintains close contact with the parents.

Before swimming lessons, the instructor checks that the children have all the swimming equipment and helps the children to prepare what they need. The instructor takes the children to the swimming pool, where they undress, put on bathing suits and prepare for the lesson. Children need special attention. They need help getting undressed, getting dressed, taking a shower and wiping because they don't know how to do it themselves, and they also need attention when getting in and out of the water. Young children do not behave well. Therefore, the help of the staff in charge of the group is needed to speed up the whole process and prevent the children from getting cold.

\section{Conclusion}

The role of the physical education instructor is very important in the organization of swimming in the pool and is of great importance in the formation of hygiene skills.

In the course of direct educational activities, medical and pedagogical control over the upbringing and health of each child is carried out taking into account his individual psychophysiological characteristics.

\section{References}

1. Bolshakova I. A. Malenkiy dolphin // Netraditsionnaya metodika obucheniya plavaniyu detey doshkolnogo vozrasta. - M .: Arkti, 2005. - 24 p.

2. Voronova E. K. Program of training swimming in kindergarten. - Sankt-Peterburg : Detstvo- press, 2003. - 80 p.

3. Grebenshchikov M. Igry i uprajneniya pri obuchenii detey plavaniyu.// Doshkolnoe vospitanie - 1991. - №11 - s.19-22. 
4. Eremeeva L. F. Nauchite rebenka plavat. - St. Petersburg .: Detstvo- press, 2005.$112 \mathrm{p}$.

5. Osokina T. I. and dr. Obuchenie plavaniyu $\vee$ detskom sadu: Kniga dlya vospitateley. - M $\therefore$ Prosveshchenie, 1991. - $157 \mathrm{p}$.

6. Ozdorovitelnыy kompleks $v$ detskom sadu: basseiy - fitobar - sauna: Metodicheskoe posobie - Kollektiv avtorov, pod red. B. B. Egorova. - M .: Gnome and D, 2004. - 108 p.

7. Protchenko T. A., Semenov YU.A. Obuchenie plavaniyu doshkolnikov i mladshix shkolnikov: Metodicheskoe posobie. - M.:Ayris press, 2003. - 80 p.

8. Chupaxa I. V., Pujaeva E. Z., Sokolova I. Yu. Zdorovesberegayushchie teknologii v obrazovatelno-vospitatelnom protsesse. - M .: Ileksa, Narodnoe obrazovanie; Stavropol: Stavropolservisshkola, 2003. - 400 p.

9. Shanina L. N. Plavanie krepost zdorovya.// Doshkolnoe vospitanie - 2001. - №6 - s. 4751. 